\title{
LETRAMENTO DIGITAL E CULTURA TECNOLÓGICA: UMA APROPRIAÇÃO ESCOLAR URGENTE
}

\author{
Cláudia Martins Moreira \\ Norma Suely Macedo Nascimento
}

\begin{abstract}
RESUMO: Este trabalho traz uma reflexão sobre o letramento digital no interior das práticas de letramento sociais. Discute-se sobre a exigência deste novo tipo de letramento no interior de uma sociedade que já vive sobre a égide da cultura escrita. Dessa forma, tanto os professores como os alunos, enquanto sujeitos sociais, necessitam dominar os recursos necessários à sobrevivência e inserção cidadã, numa cultura que é, ao mesmo tempo, alfabeticamente e digitalmente letrada. Procura-se defender a apropriação das TIC em sala de aula não como artifício meramente técnico e metodológico que visa deixar a aula mais atraente aos alunos, mas, sobretudo, pensar no uso dos diversos gêneros digitais na escola visando à formação letrada digital do aluno, que envolve não apenas o domínio técnico, mas, sobretudo, uma leitura e uso críticos dos textos digitais que povoam a vida dos sujeitos que dela se utilizam.
\end{abstract}

PALAVRAS-CHAVE: Letramento digital. Cibercultura. Ensino.

\begin{abstract}
This paper presents a reflection on digital literacy within social literacy practices. The need for this new type of literacy within a society which has already lived under written culture predominance is discussed. Thus, both teachers and students, as social subjects, need to dominate the necessary resources in order to survive and be included as citizens in a culture, which is, at the same time, alphabetically and digitally literate. ICT appropriation in classrooms is necessary, not only as technical and methodological strategies to make the lessons more attractive to students, but also as tools to think about the use of different digital genres in school. The main goal must be to accomplish digital literacy education which includes not only technical skills, but especially digital texts reading and critical use, which are part of the subject's lives who make use of it.
\end{abstract}

KEYWORDS: Digital Literacy. Cyberculture. Teaching.

\section{INTRODUÇÃO}

O surgimento das "novas" tecnologias da informação e comunicação tem não só influenciado e modificado o cotidiano das pessoas, mas também desafiado o docente, no tocante a sua prática pedagógica.

$\mathrm{Na}$ era digital, professores e alunos deparam-se com tecnologias que proporcionam amplas possibilidades de interação, produção coletiva, acesso fácil à informação, comunicação rápida, integração à comunidade virtual através do 
ciberespaço, tanto produzindo conhecimento quanto tendo acesso a novos. É um novo modo de ensinar/aprender.

Os recursos tecnológicos estão cada vez mais presentes no dia a dia das pessoas (caixas eletrônicos, celulares, e-mails entre outros), evidenciando a crescente necessidade da escola incorporá-los no seu ambiente, assim como do docente de desenvolver seu letramento digital, a fim de utilizar, satisfatoriamente as ferramentas disponíveis no ambiente virtual, visando formar estudantes ativos, criativos, críticos, enfim, verdadeiros cidadãos, capazes de produzir conhecimento e utilizá-lo para seu crescimento, contribuindo, quem sabe, para diminuir desigualdades sociais, culturais, ou até mesmo intelectuais.

Se forem usadas adequadamente, o que não significa ser a salvação dos problemas educacionais, as tecnologias podem oferecer diversas contribuições ao trabalho de sala de aula, sem falar que ela consegue ultrapassar seus muros, o que é fantástico, remetendo os sujeitos a várias dimensões, nunca antes imaginadas. Belloni é também defensor deste ponto de vista quando afirma a respeito das TIC:

É essencial, porém, que tenhamos consciência de que sua integração à educação já não é uma opção: essas tecnologias já estão no mundo, transformando todas as dimensões da vida social e econômica: cabe ao campo educacional integrá-las e tirar de suas potencialidades comunicacionais e pedagógicas o melhor proveito. (BELLONI, 2008, p. 104).

\section{A CULTURA DIGITAL COMO ESTÉTICA DO COTIDIANO}

É fato. Vivemos na cibercultura. Vivemos num mundo cercado de textos digitais dos mais diversos gêneros, alguns mais próximos da oralidade, como os chats, ICQ, MSN, outros mais próximos aos textos impressos e, assim, mais próximos à escrita formal, como os hipertextos científicos e literários; outros que ficam num meio termo entre a oralidade e a escrita, como as videoconferências, os e-mails, entre outros. Mas o que significa viver numa cibercultura? E o que é mesmo a cibercultura?

Lemos (2010) é um dos estudiosos que mais se dedica aos impactos das novas tecnologias sobre a vida em sociedade, até mesmo poderíamos falar, sobre a própria forma como os sujeitos de agrupam em comunidades. Para este autor, a tecnologia 
interfere nos ritos mais triviais do cotidiano das pessoas, provocando, como ele mesmo define, "novas formas de sociabilidade":

A cultura contemporânea, associada às tecnologias digitais (ciberespaço, simulação, tempo real, processos de virtualização, etc.), vai criar uma nova relação entre a técnica e a vida social que chamamos de cibercultura. Hoje podemos dizer que uma verdadeira estética do social cresce sob nossos olhos, alimentada pelas tecnologias do ciberespaço. (p. 15-16).

Pierre Lévy (2010) é ainda mais radical, advogando que a cibercultura não interfere apenas nas relações sociais, criando essas novas formas de viver socialmente, mas influencia na própria individualidade, interferindo na individualidade, no próprio conceito de humanidade. E por isso é que a cultura digital provoca um misto de encantamento e medo, como ele expõe em entrevista concedida a Florestan Fernandes Junior, em 2010 (LEVY, 2010).

Por outro lado, este mesmo autor (LÉVY, S.d.) acredita no papel transformador e comunista da cibercultura, por ela propiciar o acesso às diversas informações pelos mais diferentes sujeitos das mais diversas partes do mundo, produzindo um sentimento de total democracia na produção e difusão do saber (diferentemente da cultura impressa, onde tudo que era publicado passava por vários filtros, entre eles, o conselho editorial, o diagramador, o programador visual, sem falar dos agentes de controle da imprensa). Assim, o autor faz uma apologia àquilo que ele defende como papel libertador da cibercultura, que está para todos:

Acredito que seria do interesse de todos abraçarmos a perspectiva de um comunismo do conhecimento, mesmo que tenhamos que temperálo com uma porção de capitalismo cognitivo que nos permitiria traçar e reconhecer a geneologia das contribuições e, assim, darmos os créditos aos criadores. O Hipercórtex se tornaria, então, o berço de uma economia geral de valor simbólico da qual todas as comunidades poderia se alimentar. (p. 48).

Seu ponto de vista fica também explícito quando se opõe ao uso do termo "impacto das tecnologias" alegando que este termo bélico coloca a técnica como algo estranho ao homem, quando, na verdade, ela seria criada pelo mesmo: "Parece-me, pelo contrário, que não somente as técnicas são imaginadas, fabricadas e reinterpretadas 
durante seu uso pelos homens, como também é o próprio uso intensivo de ferramentas que constitui a humanidade enquanto tal”. (1999).

Esses autores citados formam o grupo dos otimistas a respeito da influência da cultura digital sobre o ser humano e a sociedade. Há, entretanto, estudiosos como Crochik (2003) que aponta os aspectos globalizantes da cultura digital e demonstra que, uma vez que a tecnologia é produto da cultura hegemônica, ela traz, na sua essência, os interesses dos grupos hegemônicos, ou seja, o capital. Nas palavras que seguem, o autor aponta para o lado nada libertador dessa tecnologia (o que pode ser contraposto ao que defende Lévy anteriormente):

[...] a democracia formal, a justiça formal, abstraem o que na sociedade as impede. [...] Ora, formalismo é imanente à tecnologia, quanto mais essa se desenvolve, mais a forma toma o lugar do conteúdo. $\mathrm{O}$ desenvolvimento da tecnologia repõe, por seu caráter formal, a dominação social. Portanto, não é simples pensar que, numa sociedade não-livre, ela pudesse ser libertadora. (p. 2003).

Esta colocação de Crochik nos inspira a considerar um outro aspecto: assim como a cultura digital é uma condição de possibilidade de democracia, uma vez que as informações estão a disposição de todos, sem censuras e a um custo razoavelmente baixo; por outro lado, o domínio dos gêneros formais que circulam na rede - os quais, além de basear-se na escrita alfabética, que nem todos dominam, exige conhecimentos enciclopédicos necessários a uma leitura não linear - é fundamental para que os textos que estão apresentados livremente na rede sejam realmente consumidos e aproveitados da melhor maneira pelos sujeitos. Assim, a cultura digital, por si, não provoca a democratização do saber; é necessário uma agência de letramento digital que possibilite, aos sujeitos sociais, os conhecimentos necessários para ler os textos digitais adequadamente e criticamente. Nesse sentido, defendemos aqui que a cultura digital, ao invés de esvaziar o papel social da escola, reafirma a sua tarefa de sistematização formal do ensino da leitura na era digital. Mas, para isso, a escola precisa conhecer de perto esta cultura e interferir a favor das massas, ao passo que, ignorando essa realidade, a escola contribui para uma subalternização das massas através da cultura digital.

\section{ALGUMAS REFLEXÕES SOBRE LETRAMENTOS E LETRAMENTO DIGITAL}


Antes de discorrer sobre letramento digital, é relevante conceituar genericamente letramento, recorrendo à definição apresentada por Kleiman (1995, p. 19): “é um conjunto de práticas sociais que usam a escrita, enquanto sistema simbólico e enquanto tecnologia, em contextos específicos, para objetivos específicos”.

Nessa perspectiva, o termo letramento digital apenas amplia, por assim dizer, a noção de letramento, quando inclui o aspecto de o indivíduo ser capaz de utilizar as TIC em prol de interesses próprios ou coletivos, com segurança e responsabilidade. De acordo com Braga (2007), letramento digital é "uma ampliação do escopo do letramento tradicional, no sentido de que as práticas letradas ocorrem no contexto digital". Freitas, por sua vez, conceitua letramento digital como

o conjunto de competências necessárias para que o indivíduo entenda e use a informação de maneira crítica e estratégica, em formatos múltiplos, vinda de variadas fontes e apresentada por meio do computador-internet, sendo capaz de atingir seus objetivos, muitas vezes compartilhados social e culturalmente. (2010, p. 339).

Observa-se que, tanto a definição de Kleiman quanto a de Freitas, atentam para o cunho social do letramento. E a despeito de uma série de reflexões acerca do letramento digital - tais como os aspectos cognitivos e fisiológicos que envolvem os processos de leitura e escritura de um texto digital, os quais se diferenciam dos processos e estratégias usados pelo sujeito durante a leitura do texto impresso - é a respeito do aspecto social deste letramento que queremos tratar neste texto, especialmente daquilo que denominamos aqui de letramento digital crítico.

Pensar num letramento digital crítico é pensar numa forma de letramento que se apropria dos diversos gêneros textuais que compõem o universo digital, ou seja, mediado pelo computador e/ou por processadores digitais tais como o celular, de uma maneira subjetiva, pessoal e autoral. Mas é também perceber que esta apropriação depende substancialmente de um domínio progressivo de estratégias de leitura e escritura próprias desse tipo de letramento. Estes aspectos foram abordados por Marcuschi (2002), o qual afirma que:

[...] parte do sucesso da nova tecnologia deve-se ao fato de reunir num só meio várias formas de expressão, tais como texto, som e imagem, o que lhe dá maleabilidade para incorporação simultânea de múltiplas 
semioses, interferindo assim na natureza dos recursos linguísticos utilizados (p. 1).

Soares (2002), neste mesmo ano, abordou ainda os aspectos cognitivos da leitura e escritura, os quais acreditamos relacionarem-se diretamente com os aspectos fisiológicos envolvidos nesses processos. A autora prioriza a análise da interferência do suporte físico em que se encontra o texto sobre os aspectos cognitivos da leitura, ou seja, procura refletir sobre como o fato de um texto estar disponível na tela do computador, propicia "movimentos de leitura" diversos daqueles propiciados pelo texto impresso, disponível no papel. É sua a seguinte afirmação:

O texto no papel é escrito e é lido linearmente, seqüencialmente - da esquerda para a direita, de cima para baixo, uma página após a outra; o texto na tela - o hipertexto - é escrito e é lido de forma multilinear, multi-sequiencial, acionando-se links ou nós que vão trazendo telas numa multiplicidade de possibilidades, sem que haja uma ordem predefinida. (p. 150).

Para efeito de diferenciação física, espacial desses dois tipos de texto, cremos que esta definição da autora é bastante oportuna; entretanto, parece-nos que esta diferenciação é um pouco exagerada em virtude de que, há muito, os estudos sobre os aspectos cognitivos da leitura, tais como o de Smith (1989) e Kintsch (1978) demonstram que a ideia de que os textos (eles referem-se aos textos impressos) são lidos linearmente é ilusória. O segundo autor inclusive projeta uma simulação da leitura fluente, compreensiva, através do modelo denominado de Construção-integração, demonstrando que o leitor fluente constitui inferências localizadas de proposições ao mesmo tempo em que integra partes do texto que não se encontram diretamente sobre seus olhos durante a leitura; além disso, ele faz retornos constantes, elaboração, confirmação ou refutação de hipóteses que ocorrem principalmente a partir dos retornos durante a leitura, ou seja, todas as características apontadas por esse autor assemelhamse a essas consideradas por Soares como se fossem próprias e exclusivas à leitura digital ou hipertextual.

O ponto de vista de Coscarelli (2010) e Marcuschi (2002) no que tange a essa questão parece coadunar com nossa perspectiva. Não estamos aqui afirmando que não

\footnotetext{
${ }^{1}$ Este termo é proposto por nós, e não pela autora.
} 
haja diferenças cognitivas entre o processamento do texto digital e o processamento do texto impresso. Acreditamos apenas que a diferença não se dê exatamente da maneira exposta, ou, ao menos, que não vejamos esses dois tipos de letramento como absolutamente diversos, como pareceu nessa definição de Soares dada acima. Esse cuidado deve-se ter principalmente porque estamos propondo uma mudança na maneira de ensinar a ler escrever, e esse radicalismo pode levar os professores ao extremo de achar que os sujeitos devam abandonar completamente os conhecimentos adquiridos a respeito de como se lê um texto alfabético e aprendam uma tecnologia de leitura e escritura completamente nova, porque este não é o caso. O letramento digital depende fundamentalmente do letramento alfabético. Quanto mais o sujeito domina a escrita alfabética, mais ele é capaz de realizar uma leitura ótima de textos digitais, pois, entre outras características, ao ler um texto digital, um sujeito que não domina bem a escrita alfabética, de modo que leia com fluência as informações textuais, precisará fixar-se, por muito tempo, diante de uma palavra, perdendo, assim, a oportunidade de percorrer as diversas informações e acionar, de maneira simultânea, as diversas semioses presentes neste texto.

Por outro lado, concordamos com Ramal (2002) quando defende que o caráter mais radicalmente diferente do texto digital hipertextual é o fato de estar mais de acordo com a maneira como pensamos do que o texto impresso. A psicologia cognitiva tem mostrado que o raciocínio, a memória, os processos semiológicos ocorrem em forma de redes, propiciam sinapses simultâneas, e é por isso que a leitura é, para nós, muitas vezes, uma atividade de alto consumo de energia, por termos que adaptar nossa forma de pensar ao texto impresso e exposto de forma linear no papel. Em outras palavras, não é a leitura que é linear, o texto impresso é que está exposto de forma linear e exige, pelo menos, algum nível de processamento linear.

Esta exposição breve sobre os aspectos cognitivos da leitura deve servir apenas para ilustrarmos alguma diferença substancial entre os textos digitais e impressos e, por extensão, o letramento digital em relação ao letramento alfabético; entretanto, não é o enfoque cognitivista que nos interessa neste trabalho, embora acreditemos que o letramento na cibercultura, tendo em vista as profundas transformações que podem provocar em nível sociocultural, alterando, como acredita Lévy (1993) a maneira como o ser humano pensa e a própria condição de humanidade (1999) (re)aproxima os estudos 
cognitivos e culturais. Interessamo-nos pela a maneira como os signos do texto digital são lidos e interpretados criticamente e ideologicamente pelos sujeitos e como a escola pode se apropriar disso e formar os alunos nesta direção.

Essa discussão nos permite refletir sobre o papel do professor e sua representação numa sociedade cercada por tecnologias das mais diversas e seu papel no ensino de habilidades que levem os jovens a um letramento digital que vá além do domínio do mouse, do teclado e do monitor. Claro que essa discussão, ora estabelecida, não se esgota aqui e nem pretende responsabilizar o professor por eventuais "falhas" ocorridas no processo educacional ou pelo uso de mecanismos mais tradicionais de ensino, desmerecendo recursos e estratégias empregados até então, mas refletir sobre a exigência presente na contemporaneidade, o letramento digital.

\section{O LUGAR DA ESCOLA EM DIREÇÃO AO LETRAMENTO DIGITAL}

As discussões empreendidas nas seções anteriores demonstram que, numa sociedade de cultura letrada, não se pode conceber um sujeito totalmente iletrado; analogamente, nesta atual sociedade de cultura digital, não podemos conceber um sujeito completamente iletrado digitalmente, por menores que forem as condições de acesso individual a essas duas tecnologias (o texto impresso e o texto digital).

E não precisamos de dados científicos para confirmar esta afirmação, basta um olhar para o Brasil de cerca de 10 anos atrás até os dias atuais para vermos o quanto o acesso às tecnologias tem sido cada mais democratizada, através do baixo custo das lan houses, da disponibilização de wireless pelos órgãos estaduais e ou municipais em locais público, da instrumentalização das escolas com computadores e acesso a internet, entre outros exemplos. Dessa forma, a aprendizagem das novas "técnicas de leitura" e de uso desse arsenal vem ocorrendo de uma maneira osmótica especialmente pelos jovens, que se sentem intensamente atraídos pelas novas tecnologias. Esse fato muitas vezes reforça a ideia errônea de que não é necessário uma escola que ensine os alunos usar os computadores e a internet. Na verdade, o que não se necessita mais é de uma escola que ensine os alunos a manusear o computador. Esse fato, por si, faz da escola 
uma agência de ensino de outras habilidades além da técnica de uso do PC, habilidades essas muito mais intelectuais, semânticas e socioculturais.

Sem dúvida, a tecnologia nos atingiu de forma assustadora e já não é possível conceber Educação desvinculada das TIC (Tecnologias da Informação e Comunicação), uma vez que permitem ampliar o conceito de aula, espaço/tempo e aprendizagem colaborativa. Entretanto, é imprescindível realizar tanto a revisão quanto atualização do papel e função do professor diante de tais transformações, adotando, dentre outras coisas, uma visão holística de sujeito, objetivando não só a aprendizagem do aluno, mas sua formação para um mundo contemporâneo globalizado e tecnológico. Segundo Ribeiro (apud COSCARELLI, 2007, p. 92)

O que se procura é o desenvolvimento geral dos sujeitos escolares, quer seja no estabelecimento de novas relações, quer seja na capacidade de síntese, de organização e sistematização, expressandose mediante múltiplas linguagens (incluindo-se a linguagem das novas tecnologias), numa situação ativa e crítica com o meio físico e social.

Para que a informática se instaure como ferramenta educacional - o que não significa ignorar ou descartar a pedagogia tradicional e todo seu rol de contribuições, mas renová-la, ajustando-as à cultura digital - é fundamental, dentre outras coisas, que o professor, enquanto mediador do processo de ensino e aprendizagem, prepare-se, no nível de letramento digital, para “operar desembaraçadamente com esse aparato tecnológico, o que não significa ser expert em informática, mas familiarizar-se com os recursos básicos necessários à utilização dessa tecnologia" (COSCARELLI, 2007, p.140).

A escola é o espaço onde os processos que ocorrem na sociedade, dos quais, hoje, o avanço tecnológico e a presença das TIC, mesclam-se e devem ser pelo menos discutidos, refletidos, nunca ignorados. Segundo Kleiman (1995) "cabe à escola, como principal agência de letramento de nossa sociedade, a função de proporcionar aos alunos o contato com as práticas de letramento digital". Magda Soares assim reflete: "recuperar o significado de um letramento já ocorrido e já internalizado, flagrando um novo letramento que está ocorrendo e apenas começa a ser internalizado" (SOARES, 2002, p. 147) é fato que não deve ser desconsiderado. 
Uma pergunta, então, torna-se necessária: o que significa "dominar" os instrumentos midiáticos?

O aluno que hoje temos está cercado por recursos tecnológicos diversificados: o uso da Internet, seja em casa ou na lan house ou no próprio aparelho celular (com seus modelos cada vez mais sofisticados), a comunicação via MSN, Facebook etc; o acesso a músicas, imagens; a postagem de fotos etc. Enfim esta é a geração que transita espontaneamente pelo mundo digital e dele se serve tanto para resolver situações triviais do cotidiano como para fazer pesquisa científica. Então, o que devemos "ensinar" a esta geração?

Acreditamos que parte da resposta esteja nas seções anteriores: precisamos ensinar os estudantes a tirar o maior proveito dos textos digitais não como meros expectadores e vorazes consumidores da informação, mas como sujeitos, coautores desses artefatos, tornando-os capazes de desfazer a opacidade por trás das mídias digitais de modo a atingir o que Lévy (S.d.) chama de transparência desses textos:

Esta estratégia de transparência vale também para as micro-batalhas onde a confiança da opinião está em jogo, no que diz respeito a posts ou artigos online. $\mathrm{O}$ leitor ou ouvinte quer saber quem paga o escritor e quais são suas filiações políticas. Quais são suas fontes? Quais são suas conexões? Cada vez menos pessoas acreditam na suposta 'objetividade' ou 'neutralidade' de textos, imagens ou pontos de vista. Sabemos que todo discurso é construído, que resulta de uma seleção e de uma formatação específica de dados, que obedece a uma agenda determinada, opera num ponto de vista singular, que se adapta mais ou menos sutilmente a certos padrões [...]. É por isso que a confiança e, portanto, a força da nova esfera pública, não se baseia mais em uma pretensão de objetividade, mas em uma demonstração de transparência. (p. 46)

Precisamos preparar os jovens para descortinar o que está por trás da neutralidade - seja ela científica, ética ou estética - corporificada num texto. Isso é verdadeiro para qualquer tipo de texto, mas enfatizamos a importância dessa orientação acerca das mídias digitais pelo fato de estas tornarem-se hoje as mais atraentes, mais sedutoras e mais facilmente disponíveis às novas gerações, com as quais a escola trabalha. Dessa forma, estaremos indo ao encontro da pedagogia crítica da leitura digital, necessidade emergente nas escolas atuais, como bem frisou Kellner (2009) a respeito da leitura de textos imagéticos, os quais, pelo seu caráter aparentemente transparente (uma vez que se pensa que a imagem é mais fiel aos referentes, àquilo que 
se aborda num texto), podem ser ainda mais passíveis de assimilação acrítica pelo leitor. Assim, sugerimos que, especialmente os textos imagéticos, sejam desconstruídos pelo professor e alunos em sala de aula, de modo a desfazerem-se suas opacidades e revelarem-se a carga ideológica, moral e pseudoestética que não são reveladas a "olho nu”.

Outra pergunta que neste momento se impõe: está o professor preparado para esta tarefa? Tem ele habilidades e conhecimentos suficientes para realizar trabalho de tamanha exigência?

Somos forçados a dizer que um dos aspectos por que a maior parte dos professores ainda não está preparada para esta tarefa diz respeito a sua formação letrada digital. Dessa forma, uma outra resposta possível é que se faz necessário mais investimentos na formação letrada digital dos agentes da educação formal (professores, gestores, coordenadores educacionais) mais especialmente os professores, por serem estes os agentes da formação letrada do estudante. Isso significa dizer que o professor precisa não apenas conhecer os diversos gêneros discursivos da linguagem digital (presentes com o advento da Internet) mas, sobretudo, saber usá-los; senão todos, ao menos aqueles mais recorrentes no dia a dia das pessoas e na vida acadêmica.

Diante de todo esse cenário emergente, a relevância do letramento digital é incontestável, o que não significa dizer, é claro, que o indivíduo obrigatoriamente deverá ser letrado de forma absoluta, seja em termos de letramento alfabético ou letramento digital (BUZATO, 2007). O que se propõe, neste texto, é demonstrar a necessidade de a escola e, consequentemente, o professor, desenvolverem novas formas de ensinar e aprender, de ler e de escrever, em razão das exigências postas pela contemporaneidade (FREITAS, 2010, p. 340).

\section{UMA CONCLUSÃO PROVISÓRIA}

As questões discutidas neste trabalho permitem-nos defender que a educação está imersa numa época que assiste a emergência da cibercultura, do ciberespaço na vida cotidiana; uma era digital, com todo o seu aparato tecnológico, o qual permite uma comunicação diferenciada e diversificada, diminuindo fronteiras e proporcionando 
hibridismos. Há, então, uma alteração nos papéis de docentes e discentes nesse contexto. Professores e alunos precisam apropriar-se conjuntamente, crítica e criativamente das TIC dando-lhes significado, tecendo possibilidades e gerando oportunidades.

O docente precisa, de fato, compreender a tecnologia como aliada, como recurso complementar à sala de aula, assumindo-a de forma transformadora, não apenas como consumidor. Por isso mesmo, é necessário pensar a formação continuada dos profissionais de educação para além da sua tarefa instrumental de tornar os professores aptos para manipular as tecnologias e utilizá-las na escola (objetivando tornar sua aula mais atraente, como se tem defendido). Não é a atração que se deve pretender fundamentalmente com o uso das TIC na escola.

É fundamental que se pense uma formação de professores que reflita sobre práticas efetivas de ensino da leitura e escrita do texto digital, de maneira a ampliar o universo de letramento dos alunos. Pensar metodologias que permitam a utilização desses recursos, de forma produtiva, os quais precisam fazer sentido na prática pedagógica, auxiliando tanto na construção e potencialização do saber quanto no desenvolvimento sociocultural, cognitivo e afetivo dos alunos. Para isso, é essencial a garantia do respeito às diferenças e a identidade de pessoas e grupos sociais inseridos nessa cultura letrada digital, para que tal prática de ensino de letramento não se transforme num instrumento de globalização e subalternização cultural.

\section{REFERÊNCIAS}

BELLONI, Maria L. Educação a distância. 5. ed. Campinas: Autores Associados, 2008.

BRAGA, D.B. "A natureza do hipertexto e suas implicações para a liberdade do leitor e o controle do autor nas interações em ambiente hipermídia”. In: Revista Anpoll, n.15, p.65-85, jul./dez. 2003.

BUZATO, Marcelo El Khouri. Inclusão digital como reinvenção do quotidiano: um estudo de caso. Disponível em : http:/dx.doi.org/101590/51413-24782008000200010. Acesso em: 13.07.12.

Letramentos Digitais e Formação de Professores. Disponível em: HTTP://www.educared.org.br/educa/img_conteudo/MarceloBuzato.pdf. Acesso em em:02.08.12. 
COSCARELLI, Carla Viana; RIBEIRO, Ana Elisa (Orgs.). Letramento digital: aspectos sociais e possibilidades pedagógicas. 2.ed. Belo Horizonte - MG: Autêntica, 2007.

A cultura escrita na sala de aula (em tempos de digitais). In: MARINHO, Marildes; CARVALHO, Gilcinei Teodoro (Org.). Cultura escrita e letramento. Belo Horizonte, MG: Editora UFMG, 2010. p. 513-526.

CROCHIK, José León. Teoria crítica e novas tecnologias da educação. In: PUCCI, B.; LASTÓRIA, L.A.C.N.; COSTA, B. C. G. (Org.). Tecnologia, cultura e formação... ainda. Auschwitz. São Paulo: Cortez, 2003.

FREITAS, Maria Tereza. Letramento digital e formação de professores. Disponível em: HTTP://www.scielo.br/scielo.php?script=sciarttext\&pid=S010246982010000300017. 2010. Acesso em: 13.07.12.

KELLNER, Douglas. Lendo imagens criticamente: em direção a uma pedagogia pósmoderna. In: SILVA, Tomaz Tadeu da (Org.). Alienígenas na sala de aula: uma introdução aos estudos culturais em educação. Petrópolis: Vozes, 2009. p. 104-131.

KLEIMAN, Ângela B. Os significados do letramento: uma nova perspectiva sobre a prática social da escrita. Campinas - SP: Mercado das Letras, 1995.

KINTSCH, W., van DIJK, T. A. Towards a model of text comprehension and production. Psychological Review, n. 85, p. 363-394. 1978.

LEMOS, André. Cibercultura: tecnologia e vida social na cultura contemporânea. Porto Alegre: Sulina, 2002.

LEVY, Pierre. As tecnologias da inteligência: o futuro do pensamento na era da informática. Tradução de Carlos Irineu da Costa. São Paulo: Editora 34, 1993.

Cibercultura. São Paulo: Editora 34, 1999.

As formas do Saber. Entrevista concedida a Florestan Fernandes Junior. Disponível em: http://www.youtube.com/watch?v=i5Ko5gGPF4w. 2010. Acesso em: 2, jul. 2012.

A espera pública do século XXI. Disponível em: http://www.moodle.ufba.br/file.php/11/artigo-pierre-levy.pdf. Acesso em: 18, ago, 2012.

MARCUSCHI, Luis A. Gêneros textuais emergentes no contexto da tecnologia digital. $50^{a}$. Reunião do GEL - Grupo de estudos Linguísticos do Estado de São Paulo, USP, São Paulo, 23-25, mai, 2002.

RAMAL, A. C. Educação na cibercultura: hipertextualidade, leitura, escrita e aprendizagem. Porto Alegre: Artmed, 2002. 
REVISTA NOVA ESCOLA, São Paulo: Fundação Victor Civita, jul. 2012.ISBN 97885-364-1376-1.

SMITH, F. Compreendendo a leitura: uma análise psicolingüística da leitura e do aprender a ler. Porto Alegre: Artes Médicas, 1989.

SOARES, Magda. Novas práticas de leitura e escrita: letramento na cibercultura. Educ. Soc., Dez 2002, vol.23, nº81, p. 143-160.

RECEBIDO EM: 01 de novembro de 2012

APROVADO EM: 04 de dezembro de 2012 